Article

\title{
Synthesis and Antitumor Activity of Triazole-Containing Sorafenib Analogs
}

\author{
Wenjing Ye, Qi Yao, Simiao Yu, Ping Gong and Mingze Qin * \\ Key Laboratory of Structure-Based Drug Design and Discovery (Shenyang Pharmaceutical University), \\ Ministry of Education, 103 Wenhua Road, Shenyang 110016, China; yewenjing@syphu.edu.cn (W.Y.); \\ 13664141520@163.com (Q.Y.); 18841498044m@sina.cn (S.Y.); gongpinggp@126.com (P.G.) \\ * Correspondence: qinmingze001@126.com; Tel./Fax: +86-24-2398-6426
}

Received: 20 September 2017; Accepted: 15 October 2017; Published: 24 October 2017

\begin{abstract}
Using a highly effective binuclear $\mathrm{Cu}$ complex as the catalyst, the 1,3-dipolar cycloaddition reactions between 16 alkynes and two azides were successfully performed and resulted in the production of 25 new triazole-containing sorafenib analogs. Several compounds were evaluated as potent antitumor agents. Among them, 4-(4-(4-(3-fluorophenyl)-1H-1,2,3-triazol-1-yl)phenoxy)$\mathrm{N}$-methylpicolinamide (8f) potently suppressed the proliferation of HT-29 cancer cells by inducing apoptosis and almost completely inhibited colony formation at a low micromolar concentration.
\end{abstract}

Keywords: binuclear $\mathrm{Cu}$ catalyst; sorafenib analogs; antitumor agents

\section{Introduction}

Although significant progress has been achieved in the treatment of tumors, it is still a major health concern worldwide. Sorafenib is a well-known antitumor agent, which potently targets several kinases such as vascular endothelial growth factor receptor (VEGFR), platelet-derived growth factor receptor (PDGFR), stem cell factor receptor (c-Kit), and the downstream protein Raf [1]. It demonstrates excellent activity against a broad range of tumor types including renal, hepatocellular, and colorectal carcinomas [2-4]. However, the relative bioavailability of sorafenib is merely $38-49 \%$, mainly due to its poor water solubility $[5,6]$. Thus, a feasible strategy for identifying antitumor agents could be the modification of sorafenib, paying equal attention to the potency and hydrophilicity of the derivatives.

The results of structure-activity relationship (SAR) analyses have indicated that the pyridine facilitates a suitable chemical interaction with Cys531 in a hinge region of B-Raf kinase, while the terminal phenyl ring occupies a hydrophobic pocket. The urea moiety connects both functional groups and forms important hydrogen-bond interactions with Glu500 and Asp593 [7-10]. Considerable studies were conducted on modification of the urea moiety, and potent compounds were identified by introducing an amide [11], rhodanine [12], or benzimidazole [13] group. From the viewpoint of medicinal chemistry, we considered that the urea moiety of sorafenib could be replaced by a 1,2,3-triazole fragment, which could act as a hydrogen-bond acceptor as well as a chemical linker between functional groups [14].

The constructing of 1,2,3-triazole cycles has been intensively studied in recent years. The $\mathrm{Cu}(\mathrm{I})$-catalyzed Huisgen 1,3-dipolar cycloaddition reaction between alkynes and azides (CuAAC) is known as one of the most efficient methods $[15,16]$. Numerous efficient catalytic systems have been developed for accelerating the catalytic process and decreasing the amount of metal catalyst needed over the past decade [17-19]. Very recently, we explored $\mathrm{Cu}$ complexes 1-3 bearing an unsymmetrical bipyridine-pyrazole-amine ligand and demonstrated their applications in the CuAAC reaction (Scheme 1) [20,21]. To the best of our knowledge, the binuclear complex 2 is currently one of the most active catalyst systems used in the CuAAC reaction. 


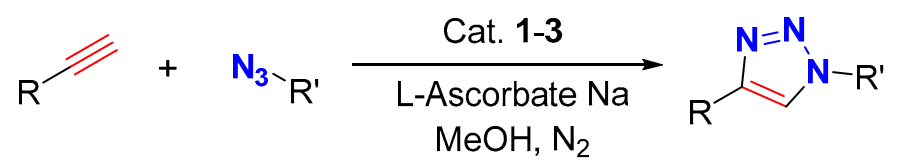<smiles></smiles>

1

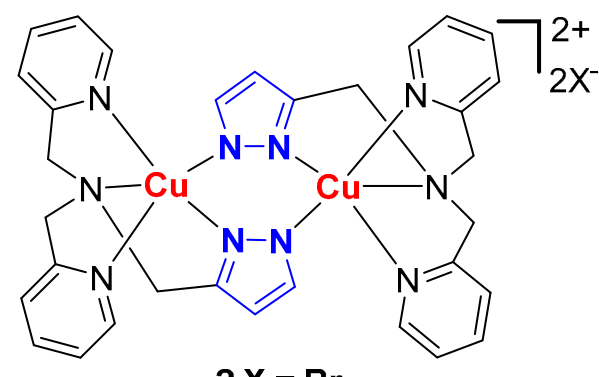

$2 \mathrm{X}=\mathrm{Br}$

$3 \mathrm{X}=\mathrm{PF}_{6}$

Scheme 1. Cu complexes bearing an unsymmetrical bipyridine-pyrazole-amine ligand and application in $\mathrm{CuAAC}$ reaction.

Herein, we reported the application of our highly active catalyst (2) in the synthesis of novel sorafenib analogs containing a 1,2,3-triazole moiety (Figure 1). The 3- $\mathrm{CF}_{3}-4-\mathrm{Cl}$ phenyl moiety in the chemical structure of sorafenib was also modified and evaluated to identify an optimal substitution pattern. The antiproliferative activity of these compounds was evaluated in HT-29 and MCF-7 cancer cell lines. The biological evaluation led to the discovery of compound $\mathbf{8 f}$, which potently suppressed the proliferation of HT-29 cells by inducing apoptosis. Furthermore, $8 \mathbf{f}$ effectively inhibited colony formation of HT-29 cells.

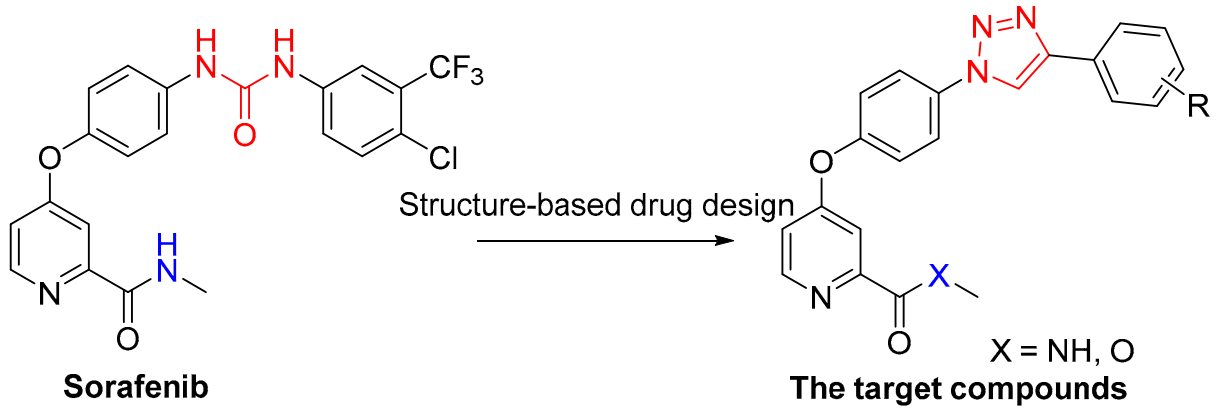

Figure 1. Design of novel sorafenib analogs.

\section{Results and Discussion}

\subsection{Chemistry}

The preparation of compounds 8a-y is described in Scheme 2. Most alkynes were obtained from commercial sources and were used without further purification. Alkynes $5 \mathbf{k}$ and $5 \mathbf{l}$ were prepared using the Seyferth-Gilbert reaction from the corresponding aldehydes $4 \mathbf{k}$ and $4 \mathbf{l}$, which were treated with 1.5 equivalents of the Bestmann-Ohira reagent in the presence of 2.0 equivalents of potassium carbonate in methanol $(\mathrm{MeOH})$ at room temperature [22]. The azides $\mathbf{7 a}$ and $\mathbf{7 b}$ were synthesized using a previously reported method [20]. Next, a library of triazolic derivatives was synthesized by cycloaddition reactions between various alkynes and azides using the binuclear complex 2 as the catalyst with a $0.1-0.3 \mathrm{~mol} \%$ catalyst loading and sodium L-ascorbate as the reductant in $\mathrm{MeOH}$ (Scheme 2). Twenty-five triazoles were obtained with excellent isolated yields between 91 and 99\%. The chemical structures of the triazoles were confirmed using nuclear magnetic resonance (NMR) 
meta-position produced compound $\mathbf{8 b}$, which exhibited significantly improved activity against the HT-29 cancer cells $\left(\mathrm{IC}_{50}=8.53 \mu \mathrm{M}\right)$. The results suggest that substituents at the meta-position were better tolerated. A similar observation was reported when the activity of $8 \mathbf{e}\left(\mathrm{R}=2-\mathrm{FPh}, \mathrm{IC}_{50}=0.84 \mu \mathrm{M}\right)$ was compared with that of $\mathbf{8 f}\left(\mathrm{R}=3-\mathrm{FPh}, \mathrm{IC}_{50}=0.20 \mu \mathrm{M}\right)$. However, the introduction of substituents at both the meta- and para-positions failed to generate potent compounds (8k and $\mathbf{8 1}$ ), which further confirmed that the para-position could not be substituted in this chemical series.

The analysis of the biological results showed that replacing the amide fragment at the 2-position of pyridine with an ester sharply decreased the activity. For example, compound $\mathbf{8 a}(X=\mathrm{NH}, \mathrm{R}=\mathrm{Ph}$; $\left.\mathrm{IC}_{50}: 0.74 \mu \mathrm{M}\right)$ exhibited potent inhibitory activity in HT-29 cells, but a 20.6-fold decrease in potency was reported for compound $\mathbf{8 q}\left(\mathrm{X}=\mathrm{O}, \mathrm{R}=\mathrm{Ph} ; \mathrm{IC}_{50}\right.$ : $\left.15.22 \mu \mathrm{M}\right)$. Reduced potency was also observed when $8 f\left(X=N H, R=3-F P h ; I_{50}: 0.20 \mu \mathrm{M}\right)$ was compared with $8 \mathbf{s}\left(X=\mathrm{O}, \mathrm{R}=3-\mathrm{FPh}\right.$; $\mathrm{IC}_{50}$ : $\left.9.12 \mu \mathrm{M}\right)$. These results indicate that a hydrogen-bond donor was necessary for activity, which was in line with the observation for sorafenib. In view of potent antiproliferative acitivity exhibited by $\mathbf{8 f}$, it was evaluated for cytotoxicity against normal cells derived from human embryonic kidney (HEK293T). Attractively, compound $\mathbf{8 f}$ was less cytotoxic for HEK293T cells, with an $\mathrm{IC}_{50}$ value of $5.32 \mu \mathrm{M}$. These results indicated that compound $\mathbf{8 f}$ was a good candidate for subsequent studies.

Table 1. Antiproliferative activities and calculated $\log P$-values of compounds $8 \mathbf{a}-\mathbf{8 y}$.

\begin{tabular}{|c|c|c|c|}
\hline \multirow{2}{*}{ Products } & \multicolumn{2}{|c|}{$\mathrm{IC}_{50}(\mu \mathrm{M})^{\mathrm{a}}$} & \multirow{2}{*}{$C \log P^{b}$} \\
\hline & HT-29 & MCF-7 & \\
\hline $8 a$ & $0.74 \pm 0.12$ & $7.53 \pm 0.65$ & 3.45 \\
\hline $8 b$ & $8.53 \pm 1.09$ & $10.17 \pm 0.77$ & 3.97 \\
\hline $8 c$ & $>100$ & $>100$ & 3.97 \\
\hline $8 d$ & $89.83 \pm 3.28$ & $>100$ & 3.30 \\
\hline $8 \mathrm{e}$ & $0.84 \pm 0.17$ & $0.33 \pm 0.02$ & 3.60 \\
\hline $8 f$ & $0.20 \pm 0.01$ & $0.61 \pm 0.12$ & 3.60 \\
\hline $8 \mathrm{~g}$ & $>100$ & $>100$ & 4.06 \\
\hline $8 \mathrm{~h}$ & $>100$ & $>100$ & 4.22 \\
\hline $8 \mathrm{i}$ & $0.55 \pm 0.08$ & $10.99 \pm 1.66$ & 4.33 \\
\hline $8 \mathbf{j}$ & $0.76 \pm 0.13$ & $26.70 \pm 3.37$ & 4.33 \\
\hline $8 k$ & $13.51 \pm 1.28$ & $50.96 \pm 2.76$ & 4.57 \\
\hline 81 & $49.20 \pm 2.39$ & $99.19 \pm 3.58$ & 4.94 \\
\hline $8 m$ & $0.60 \pm 0.05$ & $7.21 \pm 0.96$ & 2.62 \\
\hline $8 n$ & $0.58 \pm 0.13$ & $0.73 \pm 0.32$ & 3.23 \\
\hline 80 & $>100$ & $>100$ & 0.74 \\
\hline $8 p$ & $>100$ & $>100$ & 1.74 \\
\hline $8 q$ & $15.22 \pm 2.68$ & $71.92 \pm 3.66$ & 4.18 \\
\hline $8 r$ & $5.33 \pm 0.31$ & $48.33 \pm 2.56$ & 4.70 \\
\hline $8 s$ & $9.12 \pm 0.60$ & $17.06 \pm 2.17$ & 4.33 \\
\hline $8 \mathrm{t}$ & $11.81 \pm 2.31$ & $36.23 \pm 1.70$ & 4.79 \\
\hline $8 u$ & $44.54 \pm 2.28$ & $43.93 \pm 2.67$ & 5.06 \\
\hline $8 v$ & $>100$ & $>100$ & 5.06 \\
\hline $8 w$ & $9.57 \pm 1.05$ & $44.08 \pm 2.69$ & 5.30 \\
\hline $8 x$ & $54.98 \pm 2.70$ & $40.84 \pm 3.56$ & 5.67 \\
\hline $8 y$ & $8.79 \pm 0.97$ & $47.36 \pm 1.38$ & 3.96 \\
\hline sorafenib & $5.29 \pm 0.32$ & $43.30 \pm 1.36$ & 4.34 \\
\hline
\end{tabular}

a Biological data are generated from at least three independent experiments; ${ }^{\mathrm{b}} \mathrm{ClogP}$-values calculated using MarvinSketch 6.1.0.

\subsubsection{Inhibition of Colony Formation by $8 \mathrm{f}$}

Considering the potent antiproliferative activity exhibited by $\mathbf{8 f}$, a colony formation assay was conducted for a more visual result. HT-29 cells were treated with $8 \mathbf{f}$ at different concentrations $(0,0.125$, $0.25,0.5$, and $1 \mu \mathrm{M}$ ) for 14 days. As shown in Figure 2, colony formation was significantly impaired 
in the $\mathbf{8 f}$-treated group at a concentration of $0.25 \mu \mathrm{M}$. Furthermore, treatment with $0.5 \mu \mathrm{M} \mathbf{8 f}$ almost completely suppressed the colony formation.
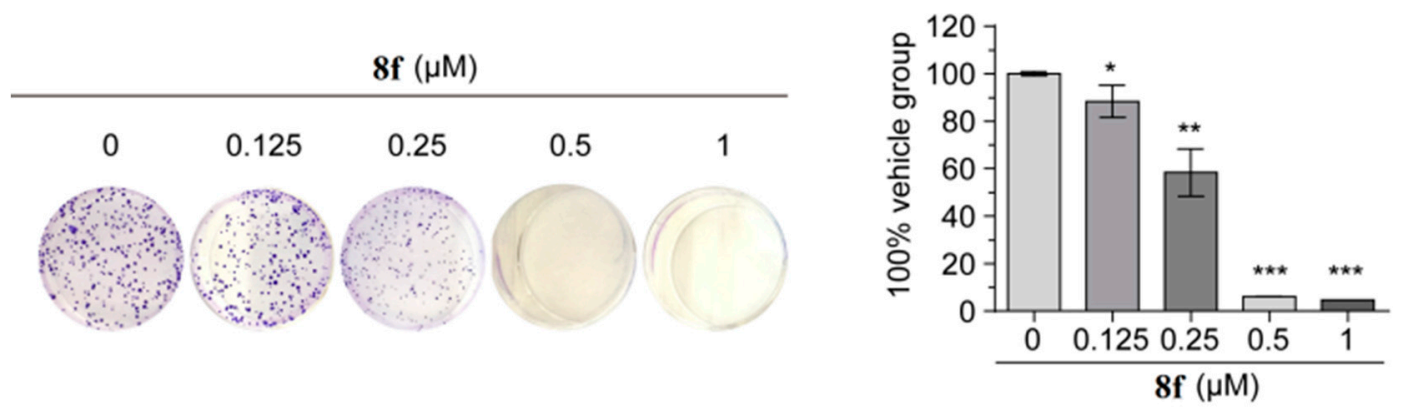

Figure 2. Representative images of colony formation of HT-29 cells treated with 8f. Relative colony formation rate is shown as mean \pm SEM. ${ }^{*} p<0.05,{ }^{* *} p<0.01$, and ${ }^{* * *} p<0.001$ versus vehicle group; $p$-values were calculated using an unpaired two-tailed Student's $t$-test.

\subsubsection{Induction of Cell Apoptosis by $8 \mathrm{f}$}

The results of the MTT and colony formation assays clearly demonstrated that $\mathbf{8 f}$ potently inhibited the proliferation of HT-29 cells. To determine whether $8 \mathbf{f}$ acted by inducing apoptosis, a biparametric cytofluorimetric analysis using propidium iodide and annexin V-fluorescein isothiocyanate staining was performed. HT-29 cells were treated with $\mathbf{8 f}$ at various concentrations $(0,0.1,0.3$, and $1 \mu \mathrm{M})$ for $72 \mathrm{~h}$ before staining and flow cytometry. As shown in Figure 3, the apoptotic rate of the HT-29 cells obviously increased from $7.57 \%$ (control) to $61.7 \%$ following treatment with $1 \mu \mathrm{M} 8 \mathrm{8f}$. The results suggest that $\mathbf{8 f}$ induced significant apoptosis of HT-29 cells in a dose-dependent manner.

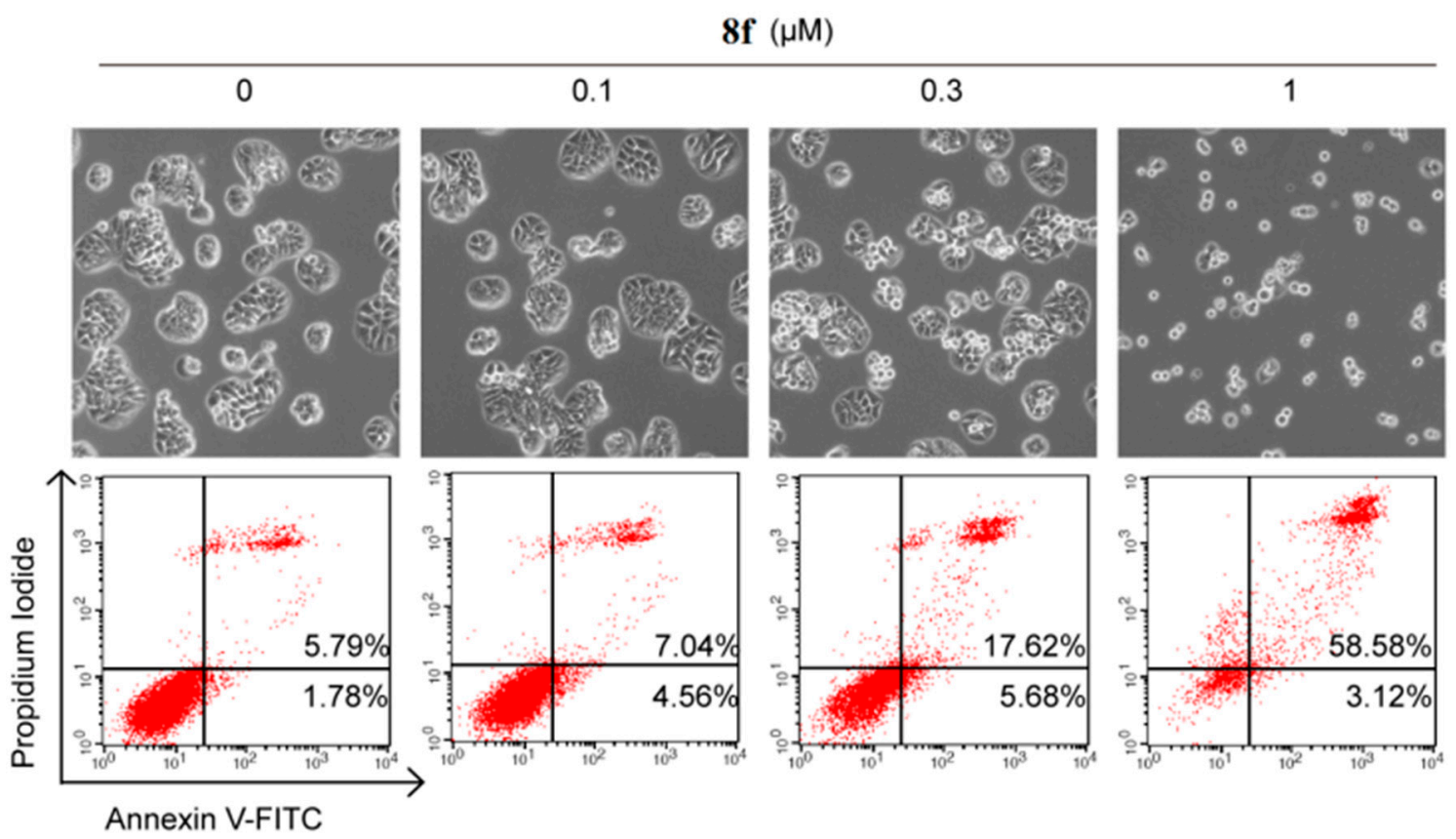

Figure 3. Effect of compound 8f on cell apoptosis in HT-29 cells. 


\section{Experimental Section}

\subsection{General Information}

The ${ }^{1} \mathrm{H}$ - and ${ }^{13} \mathrm{C}-\mathrm{NMR}$ spectra were recorded on a Bruker AV-400 spectrometer (Bruker Co., Ltd., Zurich, Switzerland), with TMS as an internal standard. Melting points were determined on a Büchi Melting Point B-540 apparatus (Büchi Labortechnik, Flawil, Switzerland). The HRMS analysis was obtained on an Agilent Technologies 6530 Accurate-Mass Q-TOF LC/MS (Version Q-TOF B.05.01, Agilent Technologies Inc., Santa Clara, CA, USA). All the alkynes except 5k and 51 were purchased from commercial sources. Intermediates $5 \mathbf{k}$ and $5 \mathbf{l}$ were prepared according to a literature procedure. The characterization of compounds $\mathbf{8 a}, \mathbf{8 h}$, and $\mathbf{8 q}$ have been reported in [20]. All of the solvents were purified according to the routine methods before being used.

\subsection{General Procedure for the Synthesis of $5 \mathbf{k}$ and $\mathbf{5 l}$}

Dimethyl-1-diazo-2-oxopropylphosphonate $(3.6 \mathrm{mmol})$ was added to a solution of aldehyde 4 $(3.0 \mathrm{mmol})$ and $\mathrm{K}_{2} \mathrm{CO}_{3}(6.0 \mathrm{mmol})$ in $\mathrm{MeOH}(3 \mathrm{~mL})$ and stirring was continued for $24 \mathrm{~h}$. The reaction mixture was diluted with $\mathrm{Et}_{2} \mathrm{O}(60 \mathrm{~mL})$, washed with an aq solution $(5 \%)$ of $\mathrm{NaHCO}_{3}(85 \mathrm{~mL})$ and water $(25 \mathrm{~mL})$ successively and dried over $\mathrm{Na}_{2} \mathrm{SO}_{4}$. After filtration and evaporation of the solvent in vacuo, the resulting residue was purified by flash column chromatography to afford the corresponding alkyne (petroleum ether (PE) as an elution solvent).

1-Chloro-4-ethynyl-2-methylbenzene (5k). Yield: 74\%, white solid. m.p.: $29.4-31.2{ }^{\circ} \mathrm{C} .{ }^{1} \mathrm{H}-\mathrm{NMR}(600 \mathrm{MHz}$, DMSO-d $\left.{ }_{6}\right) \delta 7.36(\mathrm{~d}, 1 \mathrm{H}, J=1.1 \mathrm{~Hz}, \mathrm{ArH}), 7.29-7.24(\mathrm{~m}, 2 \mathrm{H}, \mathrm{ArH}), 3.07(\mathrm{~s}, 1 \mathrm{H}, \mathrm{C} \equiv \mathrm{CH}), 2.25\left(\mathrm{~s}, 3 \mathrm{H}, \mathrm{CH}_{3}\right)$.

1-Chloro-4-ethynyl-2-(trifluoromethyl)benzene (51). Yield: 84\%, white solid. m.p.: 29.6-30.1 ${ }^{\circ} \mathrm{C} .{ }^{1} \mathrm{H}-\mathrm{NMR}$ $\left(600 \mathrm{MHz}, \mathrm{DMSO}-d_{6}\right) \delta 7.80(\mathrm{~d}, 1 \mathrm{H}, J=1.8 \mathrm{~Hz}, \mathrm{ArH}), 7.58(\mathrm{dd}, 1 \mathrm{H}, J=8.3,1.9 \mathrm{~Hz}, \mathrm{ArH}), 7.48(\mathrm{~d}, 1 \mathrm{H}$, $J=8.3 \mathrm{~Hz}, \mathrm{ArH}), 3.19$ (s, 1H, C $\equiv \mathrm{CH})$.

\subsection{General Procedure for 2-Catalyzed 1,3-Dipolar Cycloaddition Reactions}

Under $\mathrm{N}_{2}$ atmosphere, the mixture of alkyne $(0.3 \mathrm{mmol})$, azide $(0.3 \mathrm{mmol}), \mathrm{Na}$ ascorbate $(0.006 \mathrm{mmol}, 2 \mathrm{~mol} \%)$, and $0.3 \times 10^{-3} \mathrm{M}$ solution of catalyst 2 in $\mathrm{MeOH}(0.1-0.3 \mathrm{~mol} \%)$ was stirred in a $10 \mathrm{~mL}$ Schlenk tube at $25{ }^{\circ} \mathrm{C}$ for $16 \mathrm{~h}$. Evaporation of the solvents followed by purification by short column chromatography on silica gel provided the desired 1,4-disubstituted triazole product. The unreacted alkyne and azide were first eluted out with 3/1 petroleum ether (PE)/ethyl acetate, and the pure 1,4-disubstituted triazole product was then obtained by elution with pure ethyl acetate.

N-Methyl-4-(4-(4-(m-tolyl)-1H-1,2,3-triazol-1-yl)phenoxy)picolinamide (8b). Yield: 99\%, white solid. m.p.: 185-187 ${ }^{\circ}$ C. ${ }^{1} \mathrm{H}-\mathrm{NMR}\left(600 \mathrm{MHz}, \mathrm{DMSO}-d_{6}\right) \delta 9.33(\mathrm{~s}, 1 \mathrm{H}$, triazole-H), $8.82(\mathrm{q}, 1 \mathrm{H}, \mathrm{J}=4.8 \mathrm{~Hz}, \mathrm{NH}), 8.57$ $(\mathrm{d}, 1 \mathrm{H}, J=5.6 \mathrm{~Hz}, \mathrm{ArH}), 8.10(\mathrm{dt}, 2 \mathrm{H}, J=8.9,2.3 \mathrm{~Hz}, \mathrm{ArH}), 7.79$ (s, 1H, ArH), $7.75(\mathrm{~d}, 1 \mathrm{H}, J=7.7 \mathrm{~Hz}$, ArH), $7.53(\mathrm{dt}, 2 \mathrm{H}, J=8.9,2.2 \mathrm{~Hz}, \mathrm{ArH}), 7.49(\mathrm{~d}, 1 \mathrm{H}, J=2.6 \mathrm{~Hz}, \mathrm{ArH}), 7.40(\mathrm{t}, 1 \mathrm{H}, J=7.7 \mathrm{~Hz}, \mathrm{ArH})$, $7.27(\mathrm{dd}, 1 \mathrm{H}, J=5.6,2.6 \mathrm{~Hz}, \mathrm{ArH}), 7.22(\mathrm{~d}, 1 \mathrm{H}, J=7.5 \mathrm{~Hz}, \mathrm{ArH}), 2.80\left(\mathrm{~d}, 3 \mathrm{H}, J=4.9 \mathrm{~Hz}, \mathrm{NCH}_{3}\right), 2.39$ $\left(\mathrm{s}, 3 \mathrm{H}, \mathrm{CCH}_{3}\right) .{ }^{13} \mathrm{C}-\mathrm{NMR}\left(151 \mathrm{MHz}, \mathrm{DMSO}-d_{6}\right) \delta 165.18,163.72,153.28,152.66,150.67,147.49,138.21$, $134.15,130.13,128.96,125.91,122.55,122.37,122.27,119.80,114.59,109.34,26.06,21.12$. HRMS Calcd for $\mathrm{C}_{22} \mathrm{H}_{19} \mathrm{~N}_{5} \mathrm{O}_{2}[\mathrm{M}]: 385.1539$; found for $\mathrm{C}_{22} \mathrm{H}_{19} \mathrm{~N}_{5} \mathrm{O}_{2}[\mathrm{M}]: 385.1532$.

N-Methyl-4-(4-(4-(p-tolyl)-1H-1,2,3-triazol-1-yl)phenoxy)picolinamide (8c). Yield: 99\%, white solid. m.p.: 195-197 ${ }^{\circ}$ C. ${ }^{1} \mathrm{H}-\mathrm{NMR}\left(600 \mathrm{MHz}, \mathrm{DMSO}-d_{6}\right) \delta 9.30$ (s, 1H, triazole-H), $8.84(\mathrm{q}, 1 \mathrm{H}, J=4.4 \mathrm{~Hz}, \mathrm{NH}), 8.58$ $(\mathrm{d}, 1 \mathrm{H}, J=5.6 \mathrm{~Hz}, \mathrm{ArH}), 8.10(\mathrm{dt}, 2 \mathrm{H}, J=10.0,3.2 \mathrm{~Hz}, \mathrm{ArH}), 7.85(\mathrm{~d}, 2 \mathrm{H}, J=8.0 \mathrm{~Hz}, \mathrm{ArH}), 7.54-7.49$ $(\mathrm{m}, 3 \mathrm{H}, \mathrm{ArH}), 7.33(\mathrm{~d}, 2 \mathrm{H}, J=7.9 \mathrm{~Hz}, \mathrm{ArH}), 7.27(\mathrm{dd}, 1 \mathrm{H}, J=5.6,2.6 \mathrm{~Hz}, \mathrm{ArH}), 2.80(\mathrm{~d}, 3 \mathrm{H}, J=4.9 \mathrm{~Hz}$, $\left.\mathrm{NHCH}_{3}\right), 2.36\left(\mathrm{~s}, 3 \mathrm{H}, \mathrm{CCH}_{3}\right) .{ }^{13} \mathrm{C}-\mathrm{NMR}\left(151 \mathrm{MHz}, \mathrm{DMSO}-d_{6}\right) \delta 165.18,163.70,153.25,152.65,150.66$, $147.45,137.69,134.17,129.59,127.44,125.30,122.36,122.30,119.46,114.58,109.32,26.05,20.90$. HRMS Calcd for $\mathrm{C}_{22} \mathrm{H}_{19} \mathrm{~N}_{5} \mathrm{O}_{2}[\mathrm{M}]: 385.1539$; found for $\mathrm{C}_{22} \mathrm{H}_{19} \mathrm{~N}_{5} \mathrm{O}_{2}$ [M]: 385.1558 . 
4-(4-(4-(4-Methoxyphenyl)-1H-1,2,3-triazol-1-yl)phenoxy)-N-methylpicolinamide (8d). Yield: 97\%, white solid. m.p.: $215-217^{\circ} \mathrm{C} .{ }^{1} \mathrm{H}-\mathrm{NMR}\left(600 \mathrm{MHz}\right.$, DMSO- $\left.d_{6}\right) \delta 9.24(\mathrm{~s}, 1 \mathrm{H}$, triazole-H), $8.83(\mathrm{~d}, 1 \mathrm{H}, J=4.8 \mathrm{~Hz}$, $\mathrm{NH}), 8.58(\mathrm{~d}, 1 \mathrm{H}, J=5.6 \mathrm{~Hz}, \mathrm{ArH}), 8.10(\mathrm{dt}, 2 \mathrm{H}, J=8.9,3.2 \mathrm{~Hz}, \mathrm{ArH}), 7.90(\mathrm{dt}, 2 \mathrm{H}, J=8.8,2.8 \mathrm{~Hz}, \mathrm{ArH})$, 7.54-7.49 (m, 3H, ArH), $7.27(\mathrm{dd}, 1 \mathrm{H}, J=8.0,2.6 \mathrm{~Hz}, \mathrm{ArH}), 7.10(\mathrm{dt}, 2 \mathrm{H}, J=8.8,2.8 \mathrm{~Hz}, \operatorname{ArH}), 3.82(\mathrm{~s}$, $\left.3 \mathrm{H}, \mathrm{OCH}_{3}\right), 2.81\left(\mathrm{~d}, 3 \mathrm{H}, J=4.9 \mathrm{~Hz}, \mathrm{NCH}_{3}\right) .{ }^{13} \mathrm{C}-\mathrm{NMR}\left(151 \mathrm{MHz}, \mathrm{DMSO}-d_{6}\right) \delta 165.20,163.72,159.35$, 153.21, 152.65, 150.68, 147.36, 134.21, 126.75, 122.75, 122.37, 122.26, 118.89, 114.58, 114.48, 109.33, 55.24, 26.07. HRMS Calcd for $\mathrm{C}_{22} \mathrm{H}_{19} \mathrm{~N}_{5} \mathrm{O}_{3}$ [M]: 401.1488; found for $\mathrm{C}_{22} \mathrm{H}_{19} \mathrm{~N}_{5} \mathrm{O}_{3}$ [M]: 401.1471.

4-(4-(4-(2-Fluorophenyl)-1H-1,2,3-triazol-1-yl)phenoxy)-N-methylpicolinamide (8e). Yield: 98\%, white solid. m.p.: $182-183{ }^{\circ} \mathrm{C} . \mathrm{IR}\left(\mathrm{KBr}, \mathrm{cm}^{-1}\right)$ : $3395.0,1684.6,1631.3,1604.1,1566.3,1533.9,1512.4,901.8,859.3$, 837.4. ${ }^{1} \mathrm{H}-\mathrm{NMR}\left(600 \mathrm{MHz}, \mathrm{DMSO}-d_{6}\right) \delta 9.14(\mathrm{~d}, 1 \mathrm{H}, J=2.9 \mathrm{~Hz}$, triazole-H), $8.83(\mathrm{q}, 1 \mathrm{H}, J=4.4 \mathrm{~Hz}, \mathrm{NH})$, 8.57(d, $1 \mathrm{H}, J=5.6 \mathrm{~Hz}, \mathrm{ArH}), 8.21-8.14(\mathrm{~m}, 3 \mathrm{H}, \mathrm{ArH}), 7.52-7.46(\mathrm{~m}, 4 \mathrm{H}, \mathrm{ArH}), 7.42-7.37(\mathrm{~m}, 2 \mathrm{H}, \mathrm{ArH})$, $7.27(\mathrm{dd}, 1 \mathrm{H}, J=5.5,2.6 \mathrm{~Hz}, \mathrm{ArH}), 2.80\left(\mathrm{~d}, 3 \mathrm{H}, J=4.9 \mathrm{~Hz}, \mathrm{CH}_{3}\right) .{ }^{13} \mathrm{C}-\mathrm{NMR}\left(151 \mathrm{MHz}, \mathrm{DMSO}-d_{6}\right) \delta$ $165.17,163.72$, 159.43, 157.79, 153.43, 152.66, 150.68, 141.01, 140.99, 134.01, 130.23, 130.18, 127.76, 127.74, $125.09,125.07,122.78,122.29,122.09,122.02,118.00,117.91,116.27,116.13,114.61,109.34,26.06$. HRMS Calcd for $\mathrm{C}_{21} \mathrm{H}_{17} \mathrm{~N}_{5} \mathrm{O}_{2}[\mathrm{M}]$ : 389.1288; found for $\mathrm{C}_{21} \mathrm{H}_{17} \mathrm{~N}_{5} \mathrm{O}_{2}$ [M]: 389.1304 .

4-(4-(4-(3-Fluorophenyl)-1H-1,2,3-triazol-1-yl)phenoxy)-N-methylpicolinamide (8f). Yield: 99\%, white solid. m.p.: $209-210^{\circ} \mathrm{C}$. IR $\left(\mathrm{KBr}, \mathrm{cm}^{-1}\right)$ : 3403.3, 1676.7, 1630.7, 1610.4, 1589.8, 1568.9, 1538.8, 1514.7, 897.2, 862.4 , 836.4. ${ }^{1} \mathrm{H}-\mathrm{NMR}\left(600 \mathrm{MHz}\right.$, DMSO- $\left.d_{6}\right) \delta 9.42(\mathrm{~s}, 1 \mathrm{H}$, triazole-H), $8.83(\mathrm{q}, 1 \mathrm{H}, \mathrm{NH}), 8.58(\mathrm{~d}, 1 \mathrm{H}$, $J=5.6 \mathrm{~Hz}, \mathrm{ArH}), 8.09(\mathrm{~d}, 2 \mathrm{H}, J=8.9 \mathrm{~Hz}, \mathrm{ArH}), 7.82(\mathrm{~d}, 1 \mathrm{H}, J=7.8 \mathrm{~Hz}, \mathrm{ArH}), 7.76(\mathrm{~d}, 1 \mathrm{H}, J=10.1 \mathrm{~Hz}$, ArH), 7.59-7.52 (m, 3H, ArH), $7.49(\mathrm{~d}, 1 \mathrm{H}, J=2.6 \mathrm{~Hz}, \mathrm{ArH}), 7.27-7.22(\mathrm{~m}, 2 \mathrm{H}, \mathrm{ArH}), 2.80(\mathrm{~d}, 3 \mathrm{H}$, $\left.J=4.9 \mathrm{~Hz}, \mathrm{CH}_{3}\right) .{ }^{13} \mathrm{C}-\mathrm{NMR}\left(150 \mathrm{MHz}\right.$, DMSO- $\left.d_{6}\right) \delta 165.15,163.72,163.45,161.83,153.44,152.67,150.69$, $146.29(\mathrm{~d}, J=2.7 \mathrm{~Hz}), 134.03,132.61(\mathrm{~d}, J=8.6 \mathrm{~Hz}), 132.55(\mathrm{~d}, J=8.5 \mathrm{~Hz}), 131.30,131.25,122.44(\mathrm{~d}$, $J=2.8 \mathrm{~Hz}), 121.41(\mathrm{~d}, J=2.5 \mathrm{~Hz}), 120.71(\mathrm{~d}, J=2.6 \mathrm{~Hz}), 115.13,114.99,114.63,112.03,111.88,109.36$, 26.07. HRMS Calcd for $\mathrm{C}_{21} \mathrm{H}_{16} \mathrm{FN}_{5} \mathrm{O}_{2}[\mathrm{M}]^{+}$: 389.1288; found for $\mathrm{C}_{21} \mathrm{H}_{16} \mathrm{FN}_{5} \mathrm{O}_{2}[\mathrm{M}+\mathrm{H}]^{+}: 390.1355$.

4-(4-(4-(4-Chlorophenyl)-1H-1,2,3-triazol-1-yl)phenoxy)-N-methylpicolinamide (8g). Yield: 94\%, white solid. m.p.: $244-246{ }^{\circ} \mathrm{C} .{ }^{1} \mathrm{H}-\mathrm{NMR}\left(600 \mathrm{MHz}\right.$, DMSO- $\left.d_{6}\right) \delta 9.40(\mathrm{~s}, 1 \mathrm{H}$, triazole-H), $8.83(\mathrm{~d}, 1 \mathrm{H}, J=4.8 \mathrm{~Hz}$, $\mathrm{NH}), 8.58(\mathrm{~d}, 1 \mathrm{H}, J=5.6 \mathrm{~Hz}, \mathrm{ArH}), 8.09(\mathrm{~d}, 2 \mathrm{H}, J=8.9 \mathrm{~Hz}, \mathrm{ArH}), 7.98(\mathrm{~d}, 2 \mathrm{H}, J=8.5 \mathrm{~Hz}, \mathrm{ArH}), 7.60(\mathrm{~d}$, $2 \mathrm{H}, J=8.5 \mathrm{~Hz}, \mathrm{ArH}), 7.54(\mathrm{~d}, 2 \mathrm{H}, J=8.9 \mathrm{~Hz}, \mathrm{ArH}), 7.49(\mathrm{~d}, 1 \mathrm{H}, J=2.5 \mathrm{~Hz}, \mathrm{ArH}), 7.28(\mathrm{dd}, 1 \mathrm{H}, J=5.6$, $2.6 \mathrm{~Hz}, \mathrm{ArH}), 2.81\left(\mathrm{~d}, 3 \mathrm{H}, J=4.9 \mathrm{~Hz}, \mathrm{CH}_{3}\right) .{ }^{13} \mathrm{C}-\mathrm{NMR}\left(151 \mathrm{MHz}, \mathrm{DMSO}-d_{6}\right) \delta 165.16,163.72,153.39$, 152.66, 150.69, 146.30, 134.06, 132.77, 129.17, 129.14, 127.05, 122.42, 122.40, 120.33, 120.31, 114.62, 109.35, 26.07. HRMS Calcd for $\mathrm{C}_{21} \mathrm{H}_{16} \mathrm{ClN}_{5} \mathrm{O}_{2}$ [M]: 405.0993; found for $\mathrm{C}_{21} \mathrm{H}_{16} \mathrm{ClN}_{5} \mathrm{O}_{2}$ [M]: 405.0991.

N-Methyl-4-(4-(4-(2-(trifluoromethyl)phenyl)-1H-1,2,3-triazol-1-yl)phenoxy)picolinamide (8i). Yield: 99\%, white solid. m.p.: $51-54{ }^{\circ} \mathrm{C} .{ }^{1} \mathrm{H}-\mathrm{NMR}\left(600 \mathrm{MHz}, \mathrm{DMSO}-d_{6}\right) \delta 9.07(\mathrm{~s}, 1 \mathrm{H}$, triazole-H), $8.83(\mathrm{q}, 1 \mathrm{H}$, $J=4.8 \mathrm{~Hz}, \mathrm{NH}), 8.58(\mathrm{~d}, 1 \mathrm{H}, J=5.6 \mathrm{~Hz}, \mathrm{ArH}), 8.14(\mathrm{dt}, 2 \mathrm{H}, J=8.9,3.2 \mathrm{~Hz}, \mathrm{ArH}), 7.94(\mathrm{~d}, 1 \mathrm{H}, J=8.0 \mathrm{~Hz}$, ArH), 7.84-7.83 (m, 2H, ArH), 7.73-7.71 (m, 1H, ArH), 7.53-7.50 (m, 3H, ArH), 7.27 (dd, $1 \mathrm{H}, J=4.9$, $2.5 \mathrm{~Hz}, \mathrm{ArH}), 2.81\left(\mathrm{~d}, 1 \mathrm{H}, J=4.9 \mathrm{~Hz}, \mathrm{CH}_{3}\right) .{ }^{13} \mathrm{C}-\mathrm{NMR}\left(151 \mathrm{MHz}, \mathrm{DMSO}-d_{6}\right) \delta 165.17,163.71,153.45$, $152.67,150.68,144.84,133.90,132.76,132.22,129.36,128.98,127.08(\mathrm{q}, J=30.2 \mathrm{~Hz}), 126.51(\mathrm{q}, J=5.5 \mathrm{~Hz})$, $124.89,123.08,122.59,122.41,114.59,109.37$, 26.06. HRMS Calcd for $\mathrm{C}_{21} \mathrm{H}_{16} \mathrm{~F}_{3} \mathrm{~N}_{5} \mathrm{O}_{2}$ [M]: 439.1256; found for $\mathrm{C}_{21} \mathrm{H}_{16} \mathrm{~F}_{3} \mathrm{~N}_{5} \mathrm{O}_{2}[\mathrm{M}]$ : 439.1245 .

N-Methyl-4-(4-(4-(3-(trifluoromethyl)phenyl)-1H-1,2,3-triazol-1-yl)phenoxy)picolinamide (8j). Yield: 99\%, white solid. m.p.: $216-218{ }^{\circ} \mathrm{C}$. IR $\left(\mathrm{KBr}, \mathrm{cm}^{-1}\right)$ : 3391.6, 1678.7, 1594.3, 1573.2, 1542.9, 835.8, 800.3. ${ }^{1} \mathrm{H}-\mathrm{NMR}\left(600 \mathrm{MHz}, \mathrm{DMSO}-d_{6}\right) \delta 9.56(\mathrm{~s}, 1 \mathrm{H}$, triazole-H), $8.83(\mathrm{~d}, 1 \mathrm{H}, J=4.9 \mathrm{~Hz}, \mathrm{NH}), 8.59(\mathrm{~d}, 1 \mathrm{H}$, $J=5.6 \mathrm{~Hz}, \mathrm{ArH}), 8.29(\mathrm{~d}, 2 \mathrm{H}, J=4.9 \mathrm{~Hz}, \mathrm{ArH}), 8.11(\mathrm{dt}, 2 \mathrm{H}, J=8.9,2.0 \mathrm{~Hz}, \mathrm{ArH}), 7.78-7.77(\mathrm{~m}, 2 \mathrm{H}$, $\mathrm{ArH}), 7.56(\mathrm{dt}, 2 \mathrm{H}, J=8.9,2.0 \mathrm{~Hz}, \mathrm{ArH}), 7.50(\mathrm{~d}, 1 \mathrm{H}, J=2.5 \mathrm{~Hz}, \mathrm{ArH}), 7.28(\mathrm{dd}, 1 \mathrm{H}, J=5.6,2.6 \mathrm{~Hz}$, $\mathrm{ArH}), 2.81\left(\mathrm{~d}, 3 \mathrm{H}, J=4.9 \mathrm{~Hz}, \mathrm{CH}_{3}\right) .{ }^{13} \mathrm{C}-\mathrm{NMR}\left(151 \mathrm{MHz}, \mathrm{DMSO}-d_{6}\right) \delta 165.14,163.71,153.47,152.67$, $150.69,145.96,134.00,131.32,130.36,130.23\left(q, J_{F}=31.8 \mathrm{~Hz}\right), 129.11,126.87,125.06,124.84,124.81$, 123.26, 122.42, 122.38, 121.71, 121.68, 121.45, 120.96, 120.94, 114.64, 109.38, 26.06. HRMS Calcd for $\mathrm{C}_{21} \mathrm{H}_{16} \mathrm{~F}_{3} \mathrm{~N}_{5} \mathrm{O}_{2}[\mathrm{M}]:$ 439.1256; found for $\mathrm{C}_{21} \mathrm{H}_{16} \mathrm{~F}_{3} \mathrm{~N}_{5} \mathrm{O}_{2}[\mathrm{M}]: 439.1245$. 
4-(4-(4-(4-Chloro-3-methylphenyl)-1H-1,2,3-triazol-1-yl)phenoxy)-N-methylpicolinamide (8k). Yield: 99\%, white solid. m.p.: $237-238{ }^{\circ} \mathrm{C} .{ }^{1} \mathrm{H}-\mathrm{NMR}\left(600 \mathrm{MHz}, \mathrm{DMSO}-d_{6}\right) \delta 9.38(\mathrm{~s}, 1 \mathrm{H}$, triazole- $\mathrm{H}), 8.83(\mathrm{~d}, 1 \mathrm{H}$, $J=4.3 \mathrm{~Hz}, \mathrm{NH}), 8.58(\mathrm{~d}, 1 \mathrm{H}, J=5.4 \mathrm{~Hz}, \mathrm{ArH}), 8.09(\mathrm{~d}, 1 \mathrm{H}, J=8.5 \mathrm{~Hz}, \mathrm{ArH}), 7.96(\mathrm{~s}, 1 \mathrm{H}, \mathrm{ArH}), 7.80$ $(\mathrm{d}, 1 \mathrm{H}, J=7.8 \mathrm{~Hz}, \mathrm{ArH}), 7.57-7.49(\mathrm{~m}, 4 \mathrm{H}, \mathrm{ArH}), 7.28(\mathrm{~d}, 1 \mathrm{H}, J=2.9 \mathrm{~Hz}, \mathrm{ArH}), 2.81(\mathrm{~d}, 3 \mathrm{H}, J=4.6 \mathrm{~Hz}$, $\left.\mathrm{NCH}_{3}\right), 2.43$ (s, 3H, $\left.\mathrm{CCH}_{3}\right) .{ }^{13} \mathrm{C}-\mathrm{NMR}\left(151 \mathrm{MHz}, \mathrm{DMSO}-d_{6}\right) \delta$ 165.16, 163.71, 153.37, 152.66, 150.69, 146.42, 136.19, 134.07, 133.00, 129.59, 129.16, 127.93, 124.51, 122.39, 122.34, 120.20, 114.62, 109.35, 26.06, 19.75. HRMS Calcd for $\mathrm{C}_{22} \mathrm{H}_{18} \mathrm{ClN}_{5} \mathrm{O}_{2}$ [M]: 419.1149; found for $\mathrm{C}_{22} \mathrm{H}_{18} \mathrm{ClN}_{5} \mathrm{O}_{2}$ [M]: 419.1137.

4-(4-(4-(4-Chloro-3-(trifluoromethyl)phenyl)-1H-1,2,3-triazol-1-yl)phenoxy)-N-methylpicolinamide (81). Yield: 98\%, white solid. m.p.: $226-228{ }^{\circ} \mathrm{C} .{ }^{1} \mathrm{H}-\mathrm{NMR}\left(600 \mathrm{MHz}, \mathrm{DMSO}-d_{6}\right) \delta 9.58(\mathrm{~s}, 1 \mathrm{H}$, triazole-H), $8.83(\mathrm{~d}$, $1 \mathrm{H}, J=4.9 \mathrm{~Hz}, \mathrm{NH}), 8.59(\mathrm{~d}, 1 \mathrm{H}, J=5.6 \mathrm{~Hz}, \mathrm{ArH}), 8.38(\mathrm{~d}, 1 \mathrm{H}, J=1.9 \mathrm{~Hz}, \mathrm{ArH}), 8.27(\mathrm{dd}, 1 \mathrm{H}, J=8.3$, $1.8 \mathrm{~Hz}, \mathrm{ArH}), 8.10(\mathrm{dt}, 2 \mathrm{H}, J=8.9,3.2 \mathrm{~Hz}, \mathrm{ArH}), 7.91(\mathrm{~d}, 1 \mathrm{H}, J=8.4 \mathrm{~Hz}, \mathrm{ArH}), 7.56-7.50(\mathrm{~m}, 3 \mathrm{H}, \mathrm{ArH})$, $7.28(\mathrm{dd}, 1 \mathrm{H}, J=5.6,2.6 \mathrm{~Hz}, \mathrm{ArH}), 2.81\left(\mathrm{~d}, 3 \mathrm{H}, J=4.9 \mathrm{~Hz}, \mathrm{CH}_{3}\right) .{ }^{13} \mathrm{C}-\mathrm{NMR}\left(151 \mathrm{MHz}, \mathrm{DMSO}-d_{6}\right)$ $\delta$ 165.12, 163.71, 153.54, 152.67, 150.69, 145.06, 133.91, 132.62, 130.45, 130.09, 129.93, 127.52, 127.31, 124.27, 124.23, 123.70, 122.42, 122.41, 121.89, 121.28, 121.26, 114.65, 109.38, 26.06. HRMS Calcd for $\mathrm{C}_{22} \mathrm{H}_{15} \mathrm{ClF}_{3} \mathrm{~N}_{5} \mathrm{O}_{2}[\mathrm{M}]: 473.0866$; found for $\mathrm{C}_{22} \mathrm{H}_{15} \mathrm{ClF}_{3} \mathrm{~N}_{5} \mathrm{O}_{2}$ [M]: 473.0883 .

N-Methyl-4-(4-(4-(pyridin-2-yl)-1H-1,2,3-triazol-1-yl)phenoxy)picolinamide (8m). Yield: 94\%, white solid. m.p.: $200-201^{\circ} \mathrm{C} .{ }^{1} \mathrm{H}-\mathrm{NMR}\left(600 \mathrm{MHz}\right.$, DMSO- $\left.d_{6}\right) \delta 9.40(\mathrm{~s}, 1 \mathrm{H}$, triazole-H), $8.84(\mathrm{q}, 1 \mathrm{H}, J=4.5 \mathrm{~Hz}, \mathrm{NH})$, $8.68(\mathrm{~d}, 1 \mathrm{H}, J=4.7 \mathrm{~Hz}, \mathrm{ArH}), 8.58(\mathrm{~d}, 1 \mathrm{H}, J=5.6 \mathrm{~Hz}, \mathrm{ArH}), 8.19-8.14(\mathrm{~m}, 3 \mathrm{H}, \mathrm{ArH}), 7.98(\mathrm{dt}, 1 \mathrm{H}, J=7.7$, $1.6 \mathrm{~Hz}, \mathrm{ArH}), 7.52(\mathrm{~m}, 3 \mathrm{H}, \mathrm{ArH}), 7.43(\mathrm{dd}, 1 \mathrm{H}, J=7.4,4.9 \mathrm{~Hz}, \mathrm{ArH}), 7.28(\mathrm{dd}, 1 \mathrm{H}, J=5.5,2.6 \mathrm{~Hz}, \mathrm{ArH})$, 2.81, $2.80\left(\mathrm{~d}, 3 \mathrm{H}, J=4.9 \mathrm{~Hz}, \mathrm{CH}_{3}\right) .{ }^{13} \mathrm{C}-\mathrm{NMR}\left(151 \mathrm{MHz}, \mathrm{DMSO}-d_{6}\right) \delta 165.16,163.72,153.41,152.65$, $150.67,149.73,149.48,148.29,137.41,134.05,123.43,122.54,122.29,121.52,121.51,119.86,114.63,109.36$, 26.07. HRMS Calcd for $\mathrm{C}_{20} \mathrm{H}_{16} \mathrm{~N}_{6} \mathrm{O}_{2}$ [M]: 372.1335; found for $\mathrm{C}_{20} \mathrm{H}_{16} \mathrm{~N}_{6} \mathrm{O}_{2}$ [M]: 372.1340 .

N-methyl-4-(4-(4-(thiophen-2-yl)-1H-1,2,3-triazol-1-yl)phenoxy)picolinamide (8n). Yield: 92\%, white solid. m.p.: $185-188^{\circ} \mathrm{C}$. IR $\left(\mathrm{KBr}, \mathrm{cm}^{-1}\right)$ : 3381.7, 1677.0, 1631.4, 1587.3, 1571.9, 1530.8, 1511.8, 849.6, 838.6, 816.1. ${ }^{1} \mathrm{H}-\mathrm{NMR}\left(600 \mathrm{MHz}\right.$, DMSO- $\left.d_{6}\right) \delta 9.26(\mathrm{~s}, 1 \mathrm{H}$, triazole- $\mathrm{H}), 8.83(\mathrm{~d}, 1 \mathrm{H}, J=4.8 \mathrm{~Hz}, \mathrm{NH}), 8.58(\mathrm{~d}$, $1 \mathrm{H}, J=5.6 \mathrm{~Hz}, \mathrm{ArH}), 8.09$ (d, 2H, $J=8.9 \mathrm{~Hz}, \mathrm{ArH}), 7.63(\mathrm{dd}, 1 \mathrm{H}, J=5.0,0.8 \mathrm{~Hz}, \mathrm{ArH}), 7.54-7.49(\mathrm{~m}, 4 \mathrm{H}$, $\mathrm{ArH}), 7.27(\mathrm{dd}, 1 \mathrm{H}, J=5.5,2.6 \mathrm{~Hz}, \mathrm{ArH}), 7.21(\mathrm{dd}, 1 \mathrm{H}, J=4.9,3.6 \mathrm{~Hz}, \mathrm{ArH}), 2.81(\mathrm{~d}, 3 \mathrm{H}, J=4.9 \mathrm{~Hz}$, $\left.\mathrm{CH}_{3}\right) .{ }^{13} \mathrm{C}-\mathrm{NMR}\left(151 \mathrm{MHz}\right.$, DMSO- $\left.d_{6}\right) \delta 165.14,163.69,153.39,152.65,150.66,142.79,133.95,132.30$, $128.06,126.01,124.68,122.43,122.34,119.14,114.60,109.35,26.05$. HRMS Calcd for $\mathrm{C}_{19} \mathrm{H}_{15} \mathrm{~N}_{5} \mathrm{O}_{2} \mathrm{~S}[\mathrm{M}]$ : 377.0946; found for $\mathrm{C}_{19} \mathrm{H}_{15} \mathrm{~N}_{5} \mathrm{O}_{2} \mathrm{~S}[\mathrm{M}]: 377.0938$.

4-(4-(4-(Hydroxymethyl)-1H-1,2,3-triazol-1-yl)phenoxy)-N-methylpicolinamide (8o). Yield: 92\%, white solid. m.p.: $191-192{ }^{\circ} \mathrm{C} .{ }^{1} \mathrm{H}-\mathrm{NMR}\left(600 \mathrm{MHz}\right.$, DMSO- $\left.d_{6}\right) \delta 8.82(\mathrm{~d}, 1 \mathrm{H}, J=4.9 \mathrm{~Hz}, \mathrm{NH}), 8.74(\mathrm{~s}, 1 \mathrm{H}$, triazole-H), $8.57(\mathrm{~d}, 2 \mathrm{H}, J=5.6 \mathrm{~Hz}, \mathrm{ArH}), 8.06(\mathrm{dt}, 2 \mathrm{H}, J=8.9,3.2 \mathrm{~Hz}, \mathrm{ArH}), 7.49-7.46(\mathrm{~m}, 3 \mathrm{H}, \mathrm{ArH}), 7.26(\mathrm{dd}, 1 \mathrm{H}$, $J=5.6,2.6 \mathrm{~Hz}, \mathrm{ArH}), 5.39(\mathrm{t}, 1 \mathrm{H}, J=5.6 \mathrm{~Hz}, \mathrm{OH}), 4.64\left(\mathrm{~d}, 2 \mathrm{H}, J=5.5 \mathrm{~Hz}, \mathrm{CH}_{2}\right), 2.80(\mathrm{~d}, 3 \mathrm{H}, J=4.9 \mathrm{~Hz}$, $\left.\mathrm{CH}_{3}\right) .{ }^{13} \mathrm{C}-\mathrm{NMR}\left(151 \mathrm{MHz}\right.$, DMSO- $\left.d_{6}\right) \delta 165.18,163.72,153.11,152.64,150.66,149.25,134.27,122.29$, 122.26, 121.23, 114.58, 109.32, 54.98, 26.06. HRMS Calcd for $\mathrm{C}_{16} \mathrm{H}_{15} \mathrm{~N}_{5} \mathrm{O}_{3}$ [M]: 325.1175; found for $\mathrm{C}_{16} \mathrm{H}_{15} \mathrm{~N}_{5} \mathrm{O}_{3}[\mathrm{M}]: 325.1191$.

4-(4-(4-(2-Hydroxypropan-2-yl)-1H-1,2,3-triazol-1-yl)phenoxy)-N-methylpicolinamide (8p). Yield: 99\%, white solid. m.p.: $150-152{ }^{\circ} \mathrm{C} .{ }^{1} \mathrm{H}-\mathrm{NMR}\left(600 \mathrm{MHz}, \mathrm{DMSO}-d_{6}\right) \delta 8.83(\mathrm{q}, 1 \mathrm{H}, J=4.5 \mathrm{~Hz}, \mathrm{NH}), 8.65(\mathrm{~s}$, $1 \mathrm{H}$, triazole-H), $8.57(\mathrm{~d}, 1 \mathrm{H}, J=5.6 \mathrm{~Hz}, \mathrm{ArH}), 8.06(\mathrm{dt}, 2 \mathrm{H}, J=8.9,3.2 \mathrm{~Hz}, \mathrm{ArH}), 7.48-7.45(\mathrm{~m}, 3 \mathrm{H}$, ArH), $7.25(\mathrm{dd}, 1 \mathrm{H}, J=5.6,2.6 \mathrm{~Hz}, \mathrm{ArH}), 5.28(\mathrm{~s}, 1 \mathrm{H}, \mathrm{OH}), 2.81\left(\mathrm{~d}, 3 \mathrm{H}, J=4.9 \mathrm{~Hz}, \mathrm{NCH}_{3}\right), 1.55(\mathrm{~s}, 6 \mathrm{H}$, $\left.\mathrm{C}\left(\mathrm{CH}_{3}\right)_{2}\right) .{ }^{13} \mathrm{C}-\mathrm{NMR}\left(151 \mathrm{MHz}, \mathrm{DMSO}-d_{6}\right) \delta 165.19,163.72,157.03,153.01,152.64,150.66,134.34,122.25$, $122.17,119.10,114.57,109.33,67.02,30.60,26.06$. HRMS Calcd for $\mathrm{C}_{18} \mathrm{H}_{19} \mathrm{~N}_{5} \mathrm{O}_{3}$ [M]: 353.1488; found for $\mathrm{C}_{18} \mathrm{H}_{19} \mathrm{~N}_{5} \mathrm{O}_{3}[\mathrm{M}]: 353.1504$.

Methyl 4-(4-(4-(m-tolyl)-1H-1,2,3-triazol-1-yl)phenoxy)picolinate (8r). Yield: 98\%, white solid. m.p.: 147-149 ${ }^{\circ} \mathrm{C} .{ }^{1} \mathrm{H}-\mathrm{NMR}\left(600 \mathrm{MHz}, \mathrm{DMSO}-d_{6}\right) \delta 9.34(\mathrm{~s}, 1 \mathrm{H}$, triazole-H), $8.65(\mathrm{~d}, 1 \mathrm{H}, J=5.5 \mathrm{~Hz}, \mathrm{ArH})$, $8.11(\mathrm{~d}, 2 \mathrm{H}, J=8.6 \mathrm{~Hz}, \mathrm{ArH}), 7.79-7.74(\mathrm{~m}, 2 \mathrm{H}, \mathrm{ArH}), 7.56-7.52(\mathrm{~m}, 3 \mathrm{H}, \mathrm{ArH}), 7.41(\mathrm{t}, 1 \mathrm{H}, J=7.6 \mathrm{~Hz}$, $\mathrm{ArH}), 7.32(\mathrm{dd}, 1 \mathrm{H}, J=5.2,2.0 \mathrm{~Hz}, \mathrm{ArH}), 7.22(\mathrm{~d}, 1 \mathrm{H}, J=7.44 \mathrm{~Hz}, \mathrm{ArH}), 3.87\left(\mathrm{~s}, 3 \mathrm{H}, \mathrm{OCH}_{3}\right), 2.40(\mathrm{~s}, 3 \mathrm{H}$, 
$\left.\mathrm{CCH}_{3}\right) .{ }^{13} \mathrm{C}-\mathrm{NMR}\left(151 \mathrm{MHz}\right.$, DMSO- $\left.d_{6}\right) \delta 164.82,164.72,153.22,151.92,149.74,147.53,138.24,134.19$, $130.13,128.99,125.93,122.57,122.28,119.78,115.51,112.89,52.67,21.14$. HRMS Calcd for $\mathrm{C}_{22} \mathrm{H}_{18} \mathrm{~N}_{4} \mathrm{O}_{3}$ [M]: 386.1379; found for $\mathrm{C}_{22} \mathrm{H}_{18} \mathrm{~N}_{4} \mathrm{O}_{3}$ [M]: 386.1370 .

Methyl 4-(4-(4-(3-fluorophenyl)-1H-1,2,3-triazol-1-yl)phenoxy)picolinate (8s). Yield: 96\%, white solid. m.p.: 154-157 ${ }^{\circ} \mathrm{C} .{ }^{1} \mathrm{H}-\mathrm{NMR}\left(600 \mathrm{MHz}, \mathrm{CDCl}_{3}\right) \delta 9.42(\mathrm{~s}, 1 \mathrm{H}$, triazole-H), $8.65(\mathrm{~d}, 1 \mathrm{H}, J=5.5 \mathrm{~Hz}, \mathrm{ArH}), 8.08(\mathrm{~d}$, $2 \mathrm{H}, J=8.6 \mathrm{~Hz}, \mathrm{ArH}), 7.81(\mathrm{~d}, 1 \mathrm{H}, J=7.6 \mathrm{~Hz}, \mathrm{ArH}), 7.75(\mathrm{~d}, 1 \mathrm{H}, J=9.9 \mathrm{~Hz}, \mathrm{ArH}), 7.58-7.53(\mathrm{~m}, 4 \mathrm{H}, \mathrm{ArH})$, $7.32(\mathrm{dd}, 1 \mathrm{H}, J=5.2,2.0 \mathrm{~Hz}, \mathrm{ArH}), 7.25(\mathrm{t}, 1 \mathrm{H}, J=7.1 \mathrm{~Hz}, \mathrm{ArH}), 3.86\left(\mathrm{~s}, 3 \mathrm{H}, \mathrm{CH}_{3}\right) .{ }^{13} \mathrm{C}-\mathrm{NMR}(150 \mathrm{MHz}$, DMSO- $\left.d_{6}\right) \delta 164.84,164.70,163.47,161.86,153.39,151.96,149.76,146.34,134.07,132.62,132.56,131.35$, 131.29, 122.46, 122.34, 121.46, 120.70, 115.56, 115.17, 115.03, 112.93, 112.06, 111.91, 52.70. HRMS Calcd for $\mathrm{C}_{21} \mathrm{H}_{15} \mathrm{FN}_{4} \mathrm{O}_{3}[\mathrm{M}]: 390.1128$; found for $\mathrm{C}_{21} \mathrm{H}_{15} \mathrm{FN}_{4} \mathrm{O}_{3}[\mathrm{M}]$ : 390.1142 .

Methyl 4-(4-(4-(4-chlorophenyl)-1H-1,2,3-triazol-1-yl)phenoxy)picolinate (8t). Yield: 99\%, white solid. m.p.: 173-175 ${ }^{\circ} \mathrm{C}$. IR $\left(\mathrm{KCl}, \mathrm{cm}^{-1}\right)$ : 3415.6, 1717.4, 1631.5, 1608.1, 1586.3, 884.0, 866.4, 855.6, 835.6. ${ }^{1} \mathrm{H}-\mathrm{NMR}$ $\left(600 \mathrm{MHz}, \mathrm{DMSO}-d_{6}\right) \delta 9.40(\mathrm{~s}, 1 \mathrm{H}$, triazole-H), $8.65(\mathrm{~d}, 1 \mathrm{H}, J=5.6 \mathrm{~Hz}, \mathrm{ArH}), 8.09(\mathrm{~d}, 2 \mathrm{H}, J=8.7 \mathrm{~Hz}$, $\mathrm{ArH}), 7.98(\mathrm{~d}, 2 \mathrm{H}, J=8.3 \mathrm{~Hz}, \mathrm{ArH}), 7.60(\mathrm{~d}, 2 \mathrm{H}, J=8.2 \mathrm{~Hz}, \mathrm{ArH}), 7.56-7.53(\mathrm{~m}, 3 \mathrm{H}, \mathrm{ArH}), 7.32(\mathrm{dd}, 1 \mathrm{H}$, $J=5.3,1.7 \mathrm{~Hz}, \mathrm{ArH}), 3.86\left(\mathrm{~s}, 3 \mathrm{H}, \mathrm{CH}_{3}\right) .{ }^{13} \mathrm{C}-\mathrm{NMR}\left(151 \mathrm{MHz}, \mathrm{DMSO}-d_{6}\right) \delta 164.82,164.69,153.34,151.93$, $149.75,146.35,134.09,132.80,129.18,129.14,127.07,122.42,122.30,120.28,115.53,112.90,52.67$. HRMS Calcd for $\mathrm{C}_{21} \mathrm{H}_{15} \mathrm{ClN}_{4} \mathrm{O}_{3}[\mathrm{M}]$ : 406.0833; found for $\mathrm{C}_{21} \mathrm{H}_{15} \mathrm{ClN}_{4} \mathrm{O}_{3}$ [M]: 406.0827 .

Methyl 4-(4-(4-(2-(trifluoromethyl)phenyl)-1H-1,2,3-triazol-1-yl)phenoxy)picolinate (8u). Yield: 99\%, white solid. m.p.: 87-88 ${ }^{\circ} \mathrm{C} .{ }^{1} \mathrm{H}-\mathrm{NMR}\left(600 \mathrm{MHz}\right.$, DMSO- $\left.d_{6}\right) \delta 9.06(\mathrm{~s}, 1 \mathrm{H}$, triazole-H), $8.65(\mathrm{~d}, 1 \mathrm{H}, J=5.5 \mathrm{~Hz}$, $\operatorname{ArH}), 8.14(\mathrm{~d}, 2 \mathrm{H}, J=8.8 \mathrm{~Hz}, \operatorname{ArH}), 7.93(\mathrm{~d}, 1 \mathrm{H}, J=7.9 \mathrm{~Hz}, \mathrm{ArH}), 7.83-7.82(\mathrm{~m}, 2 \mathrm{H}, \mathrm{ArH}), 7.72(\mathrm{t}$, $1 \mathrm{H}, J=6.8 \mathrm{~Hz}, \mathrm{ArH}), 7.55-7.52(\mathrm{~m}, 3 \mathrm{H}, \mathrm{ArH}), 7.32(\mathrm{dd}, 1 \mathrm{H}, J=5.5,2.4 \mathrm{~Hz}, \mathrm{ArH}), 3.86\left(\mathrm{~s}, 3 \mathrm{H}, \mathrm{CH}_{3}\right)$. ${ }^{13}$ C-NMR (151 MHz, DMSO-d $\left.d_{6}\right) \delta 164.81,164.71,153.39,151.92,149.75,144.88,133.93,132.78,132.25$, $129.39,128.98,127.11(\mathrm{q}, J=30.0 \mathrm{~Hz}), 126.53(\mathrm{q}, J=5.4 \mathrm{~Hz}), 124.91,123.10,122.58,122.33,115.51,112.89$, 52.67. HRMS Calcd for $\mathrm{C}_{22} \mathrm{H}_{15} \mathrm{~F}_{3} \mathrm{~N}_{4} \mathrm{O}_{3}[\mathrm{M}]:$ 440.1096; found for $\mathrm{C}_{22} \mathrm{H}_{15} \mathrm{~F}_{3} \mathrm{~N}_{4} \mathrm{O}_{3}$ [M]: 440.1062.

Methyl 4-(4-(4-(3-(trifluoromethyl)phenyl)-1H-1,2,3-triazol-1-yl)phenoxy)picolinate (8v). Yield: 93\%, white solid. m.p.: $172-174{ }^{\circ} \mathrm{C} .{ }^{1} \mathrm{H}-\mathrm{NMR}\left(600 \mathrm{MHz}, \mathrm{CDCl}_{3}\right) \delta 9.55(\mathrm{~s}, 1 \mathrm{H}$, triazole-H), $8.65(\mathrm{~d}, 1 \mathrm{H}, J=5.6 \mathrm{~Hz}$, ArH), $8.28(\mathrm{~d}, 2 \mathrm{H}, J=5.0 \mathrm{~Hz}, \mathrm{ArH}), 8.11(\mathrm{dt}, 2 \mathrm{H}, J=8.9,3.3 \mathrm{~Hz}, \mathrm{ArH}), 7.77-7.76(\mathrm{~m}, 2 \mathrm{H}, \mathrm{ArH}), 7.55-7.53$ $(\mathrm{m}, 3 \mathrm{H}, \mathrm{ArH}), 7.32(\mathrm{dd}, 1 \mathrm{H}, J=5.6,2.6 \mathrm{~Hz}, \mathrm{ArH}), 3.86\left(\mathrm{~s}, 3 \mathrm{H}, \mathrm{CH}_{3}\right) .{ }^{13} \mathrm{C}-\mathrm{NMR}\left(151 \mathrm{MHz}, \mathrm{DMSO}-d_{6}\right) \delta$ $164.78,164.64,153.39,151.90,149.73,145.97,134.00,131.29,130.33,130.21$ (q, $J=31.9 \mathrm{~Hz}), 129.08,126.85$, 125.05, 124.82, 124.80, 123.24, 122.34, 122.28, 121.69, 121.67, 121.44, 120.90, 120.88, 115.51, 112.90, 52.63 . HRMS Calcd for $\mathrm{C}_{22} \mathrm{H}_{15} \mathrm{~F}_{3} \mathrm{~N}_{4} \mathrm{O}_{3}$ [M]: 440.1096; found for $\mathrm{C}_{22} \mathrm{H}_{15} \mathrm{~F}_{3} \mathrm{~N}_{4} \mathrm{O}_{3}$ [M]: 440.1102 .

Methyl 4-(4-(4-(4-chloro-3-methylphenyl)-1H-1,2,3-triazol-1-yl)phenoxy)picolinate (8w). Yield: 99\%, white solid. m.p.: $177-178{ }^{\circ} \mathrm{C} .{ }^{1} \mathrm{H}-\mathrm{NMR}\left(600 \mathrm{MHz}\right.$, DMSO- $\left.d_{6}\right) \delta 9.38(\mathrm{~s}, 1 \mathrm{H}$, triazole-H), $8.65(\mathrm{~d}, 1 \mathrm{H}, J=5.5 \mathrm{~Hz}$, ArH), $8.10(\mathrm{dt}, 2 \mathrm{H}, J=6.8,3.3 \mathrm{~Hz}, \mathrm{ArH}), 7.95(\mathrm{~d}, 1 \mathrm{H}, J=1.5 \mathrm{~Hz}, \mathrm{ArH}), 7.80(\mathrm{dd}, 1 \mathrm{H}, J=8.2,1.8 \mathrm{~Hz}$, $\mathrm{ArH}), 7.57-7.53(\mathrm{~m}, 4 \mathrm{H}, \mathrm{ArH}), 7.32(\mathrm{dd}, 1 \mathrm{H}, J=5.6,2.6 \mathrm{~Hz}, \mathrm{ArH}), 3.86\left(\mathrm{~s}, 3 \mathrm{H}, \mathrm{OCH}_{3}\right), 2.42(\mathrm{~s}, 3 \mathrm{H}$, $\left.\mathrm{CCH}_{3}\right) .{ }^{13} \mathrm{C}-\mathrm{NMR}\left(151 \mathrm{MHz}\right.$, DMSO- $\left.d_{6}\right) \delta 164.84,164.71,153.33,151.95,149.76,146.48,136.23,134.11$, 133.06, 129.62, 129.16, 127.97, 124.55, 122.37, 122.32, 120.17, 115.55, 112.93, 52.70, 19.78. HRMS Calcd for $\mathrm{C}_{22} \mathrm{H}_{17} \mathrm{ClN}_{4} \mathrm{O}_{3}$ [M]: 420.0989; found for $\mathrm{C}_{22} \mathrm{H}_{17} \mathrm{ClN}_{4} \mathrm{O}_{3}$ [M]: 420.1007 .

Methyl 4-(4-(4-(4-chloro-3-(trifluoromethyl)phenyl)-1H-1,2,3-triazol-1-yl)phenoxy)picolinate (8x). Yield: 99\%, white solid. m.p.: $175-17{ }^{\circ} \mathrm{C} .{ }^{1} \mathrm{H}-\mathrm{NMR}\left(600 \mathrm{MHz}, \mathrm{DMSO}-d_{6}\right) \delta 9.59(\mathrm{~s}, 1 \mathrm{H}$, triazole-H), $8.66(\mathrm{~d}, 1 \mathrm{H}$, $J=5.6 \mathrm{~Hz}, \mathrm{ArH}), 8.38(\mathrm{~d}, 1 \mathrm{H}, J=1.8 \mathrm{~Hz}, \mathrm{ArH}), 8.27(\mathrm{dd}, 1 \mathrm{H}, J=8.3,1.9 \mathrm{~Hz}, \mathrm{ArH}), 8.09(\mathrm{dt}, 2 \mathrm{H}, J=8.9$, $1.9 \mathrm{~Hz}, \mathrm{ArH}), 7.92(\mathrm{~d}, 1 \mathrm{H}, J=8.4 \mathrm{~Hz}, \mathrm{ArH}), 7.56-7.54(\mathrm{~m}, 3 \mathrm{H}, \mathrm{ArH}), 7.33(\mathrm{dd}, 1 \mathrm{H}, J=5.5,2.5 \mathrm{~Hz}$, $\mathrm{ArH}), 3.87\left(\mathrm{~s}, 3 \mathrm{H}, \mathrm{CH}_{3}\right) .{ }^{13} \mathrm{C}-\mathrm{NMR}\left(151 \mathrm{MHz}\right.$, DMSO-d $\left.d_{6}\right) \delta 164.81,164.64,153.47,151.93,149.75,145.09$, $133.93,132.62,130.46,130.12,129.92,127.52$ (q, $J=30.8 \mathrm{~Hz}), 124.27,123.71,122.39,122.31,121.90,121.20$, 115.55, 112.94, 52.67. HRMS Calcd for $\mathrm{C}_{22} \mathrm{H}_{14} \mathrm{ClF}_{3} \mathrm{~N}_{4} \mathrm{O}_{3}$ [M]: 474.0707; found for $\mathrm{C}_{22} \mathrm{H}_{14} \mathrm{ClF}_{3} \mathrm{~N}_{4} \mathrm{O}_{3}$ [M]: 474.0730 . 
Methyl 4-(4-(4-(thiophen-2-yl)-1H-1,2,3-triazol-1-yl)phenoxy)picolinate (8y). Yield: 99\%, white solid. m.p.: 152-153 ${ }^{\circ} \mathrm{C} .{ }^{1} \mathrm{H}-\mathrm{NMR}\left(600 \mathrm{MHz}, \mathrm{DMSO}-d_{6}\right) \delta 9.26$ (s, 1H, triazole-H), $8.65(\mathrm{~d}, 1 \mathrm{H}, J=5.5 \mathrm{~Hz}, \mathrm{ArH}), 8.09$ $(\mathrm{d}, 2 \mathrm{H}, J=8.9 \mathrm{~Hz}, \mathrm{ArH}), 7.63(\mathrm{~d}, 1 \mathrm{H}, J=5.0 \mathrm{~Hz}, \mathrm{ArH}), 7.56-7.52(\mathrm{~m}, 4 \mathrm{H}, \mathrm{ArH}), 7.32(\mathrm{dd}, 1 \mathrm{H}, J=5.5$, $2.5 \mathrm{~Hz}, \mathrm{ArH}), 7.21(\mathrm{dt}, 1 \mathrm{H}, J=3.7,1.2 \mathrm{~Hz}, \mathrm{ArH}), 3.87\left(\mathrm{~s}, 3 \mathrm{H}, \mathrm{CH}_{3}\right) .{ }^{13} \mathrm{C}-\mathrm{NMR}\left(151 \mathrm{MHz}, \mathrm{DMSO}-d_{6}\right)$ $\delta 164.82,164.69,153.36,151.93,149.75,142.85,133.99,132.29,128.11,126.06,124.74,122.46,122.27$, 119.12, 115.53, 112.91, 52.67. HRMS Calcd for $\mathrm{C}_{19} \mathrm{H}_{14} \mathrm{~N}_{4} \mathrm{O}_{3} \mathrm{~S}[\mathrm{M}]$ : 378.0787; found for $\mathrm{C}_{19} \mathrm{H}_{14} \mathrm{~N}_{4} \mathrm{O}_{3} \mathrm{~S}$ [M]: 378.0797 .

\subsection{Cell Viability Assay}

The viability of HT-29, MCF-7, and HEK293T cells was determined using an MTT (3-(4,5-dimethylthiazol-2-yl)-2,5-diphenyltetrazolium bromide) assay. These cancer cell lines were cultured in minimum essential medium supplemented with $10 \%$ foetal bovine serum.

Approximately $4 \times 10^{3}$ cells were suspended in cell culture medium, plated in a 96-well plate and incubated at $37{ }^{\circ} \mathrm{C}$ in $5 \% \mathrm{CO}_{2}$ for $24 \mathrm{~h}$. The test compounds were added to the culture medium and incubated for a further $72 \mathrm{~h}$. Fresh MTT was then added to each well at a final concentration of $5 \mu \mathrm{g} / \mathrm{mL}$, and incubated with the cells at $37^{\circ} \mathrm{C}$ for $4 \mathrm{~h}$. The formazan crystals in each well were dissolved in $100 \mu \mathrm{L}$ DMSO, and the absorbance at $492 \mathrm{~nm}$ (MTT formazan wavelength) and $630 \mathrm{~nm}$ (reference wavelength) was measured by a microplate reader. The reported $\mathrm{IC}_{50}$ results represented averages of at least three determinations and were calculated using the Bacus Laboratories Incorporated Slide Scanner (Bliss) software.

\subsection{Colony Formation Assay}

Logarithmic phase HT-29 cells were seeded into 6-well plates at a concentration of 500 cells per well. The next day, cells were treated with 8 f at $0.125,0.25,0.5$, and $1 \mu \mathrm{M}$. Colonies were fixed with methanol at room temperature for $15 \mathrm{~min}$ and then stained with a solution of $0.1 \%$ crystal violet diluted by phosphate buffered saline (PBS) from 0.5\% crystal violet (dissolved in methanol) for 15 min and then washed by water. The stained colonies were then photographed and dissolved by $33 \%$ acetic acid. Optical density of absorbance was read at $570 \mathrm{~nm}$.

\subsection{Apoptosis Assay}

Apoptosis of HT-29 cells was detected using a flow cytometric assay. Briefly, cells were seeded in 6-well plates and incubated overnight. The following day, cells were treated with different concentrations of compound $8 \mathrm{f}$ for $72 \mathrm{~h}$. The cells and supernatants were harvested and washed twice with cold PBS and then resuspended in $100 \mu \mathrm{L} 1 \times$ Binding Buffer. $5 \mu \mathrm{L}$ of FITC Annexin V and $5 \mu \mathrm{L}$ PI were added in each tube and the cells were then gently vortexed incubated for 15 min at RT $\left(25^{\circ} \mathrm{C}\right)$ in the dark. In addition, $400 \mu \mathrm{L}$ of $1 \times$ Binding Buffer was then added to each tube. The stained cells were analyzed by a flow cytometer (Thermo Fisher Scientific, San Jose, CA, USA).

\section{Conclusions}

In summary, we demonstrated the synthetic application of our highly active CuAAC reaction catalyst in preparing a novel series of sorafenib analogs. The binuclear $\mathrm{Cu}$ catalyst exhibited a satisfactory performance in the synthesis of the target compounds. At $0.1-0.3 \mathrm{~mol} \%$ catalyst loading, all triazole products were obtained at $91-99 \%$ isolated yields. Using this catalytic system, 25 new compounds were prepared effectively and were evaluated biologically. The MTT and colony formation assays demonstrated that compound 8f potently inhibited the proliferation of HT-29 cells. The flow cytometric assay suggested that $\mathbf{8 f}$ caused significant apoptosis of HT-29 cells in a dose-dependent manner.

According to the chemical structural characteristics of $\mathbf{8 f}$, we considered it to be a kinase inhibitor. Actually, we attempted to identify its biological target by screening it against a panel of kinases including B-Raf, VEGFR-3, PDGFR $\alpha$, fibroblast growth factor receptor 1 (FGFR1), c-Kit, TRAF2 and 
NCK interacting kinase (TNIK), ret proto-oncogene (RET), cyclin-dependent 2 (CDK2), checkpoint kinase 1 (CHK1), and cyclin-dependent kinase 4 (CDK4). However, none of these kinases were significantly inhibited (Supplementary materials Table S1). These results indicated that $8 \mathrm{f}$ acted quite differently from sorafenib. More detailed investigations of the mechanisms of action of these compounds are in progress in our laboratory. Studies of the SARs indicated that a fluorine atom at the meta-position of the terminal phenyl ring was well tolerated, rather than the $3-\mathrm{CF}_{3}-4-\mathrm{Cl}$ group in sorafenib. The hydrogen-bond donor at the 2-position of pyridine was indispensable for the activity of this chemical series. These findings all provide potentially valuable guidance for designing more powerful compounds.

Supplementary Materials: Supplementary materials are available online. Table S1: Enzymatic screening of selected compounds.

Acknowledgments: This work was supported by the National Natural Science Foundation of China (81502924 and 21502120) and the Innovation Training Project of Liaoning Province (201610163013).

Author Contributions: Mingze Qin and Wenjing Ye designed and wrote the paper; Qi Yao, Simiao Yu, and Ping Gong carried out the experiments. All authors have read and approved the final manuscript.

Conflicts of Interest: The authors have declared no conflict of interest.

\section{References}

1. Guida, T.; Anaganti, S.; Provitera, L.; Gedrich, R.; Sullivan, E.; Wilhelm, S.; Santoro, M.; Carlomagno, F. Sorafenib inhibits imatinib-resistant KIT and platelet-derived growth factor receptor beta gatekeeper mutants. Clin. Cancer Res. 2007, 13, 3363-3369. [CrossRef] [PubMed]

2. Wilhelm, S.; Carter, C.; Lynch, M.; Lowinger, T.; Dumas, J.; Smith, R.A.; Schwartz, B.; Simantov, R.; Kelley, S. Discovery and development of sorafenib: A multikinase inhibitor for treating cancer. Nat. Rev. Drug Discov. 2006, 5, 835-844. [CrossRef] [PubMed]

3. Musumeci, F.; Radi, M.; Brullo, C.; Schenone, S. Vascular endothelial growth factor (VEGF) receptors: Drugs and new inhibitors. J. Med. Chem. 2012, 55, 10797-10822. [CrossRef] [PubMed]

4. Wilhelm, S.; Adnane, L.; Newell, P.; Villanueva, A.; Llovet, J.; Lynch, M. Preclinical overview of sorafenib, a multikinase inhibitor that targets both Raf and VEGF and PDGF receptor tyrosine kinase signaling. Mol. Cancer Ther. 2008, 7, 3129-3140. [CrossRef] [PubMed]

5. Drug Bank. Sorafenib Drug Card DB00398. Available online: https://www.drugbank.ca/drugs/DB00398 (accessed on 18 October 2017).

6. Liu, C.; Chen, Z.; Chen, Y.; Lu, J.; Li, Y.; Wang, S.; Wu, G.; Qian, F. Improving oral bioavailability of sorafenib by optimizing the "spring" and "parachute" based on molecular interaction mechanisms. Mol. Pharm. 2016, 13, 599-608. [CrossRef] [PubMed]

7. Zhan, W.; Li, Y.; Huang, W.; Zhao, Y.; Yao, Z.; Yu, S.; Yuan, S.; Jiang, F.; Yao, S.; Li, S. Design, synthesis and antitumor activities of novel bis-aryl ureas derivatives as Raf kinase inhibitors. Bioorg. Med. Chem. 2012, 20, 4323-4329. [CrossRef] [PubMed]

8. Chu, Y.; Cheng, H.; Tian, Z.; Zhao, J.; Li, G.; Chu, Y.; Sun, C.; Li, W. Rational drug design of indazole-based diarylurea derivatives as anticancer agents. Chem. Biol. Drug Des. 2017, 90, 609-617. [CrossRef] [PubMed]

9. Zhao, C.; Wang, R.; Li, G.; Xue, X.; Sun, C.; Qu, X.; Li, W. Synthesis of indazole based diarylurea derivatives and their antiproliferative activity against tumor cell lines. Bioorg. Med. Chem. Lett. 2013, 23, 1989-1992. [CrossRef] [PubMed]

10. Yao, J.; He, Z.; Chen, J.; Sun, W.; Fang, H.; Xu, W. Design, synthesis and biological activities of sorafenib derivatives as antitumor agents. Bioorg. Med. Chem. Lett. 2012, 22, 6549-6553. [CrossRef] [PubMed]

11. Wang, W.; Wu, C.; Wang, J.; Luo, R.; Wang, C.; Liu, X.; Li, J.; Zhu, W.; Zheng, P. Synthesis, activity and docking studies of phenylpyrimidine-carboxamide sorafenib derivatives. Bioorg. Med. Chem. 2016, 24 , 6166-6173. [CrossRef] [PubMed]

12. Li, W.; Zhai, X.; Zhong, Z.; Li, G.; Pu, Y.; Gong, P. Design, synthesis and evaluation of novel rhodaninecontaining sorafenib analogs as potential antitumor agents. Arch. Pharm. 2011, 11, 349-357. [CrossRef] [PubMed] 
13. Ramurthy, S.; Subramanian, S.; Aikawa, M.; Amiri, P.; Costales, A.; Dove, J.; Fong, S.; Jansen, J.M.; Levine, B.; Ma, S.; et al. Design and synthesis of orally bioavailable benzimidazoles as Raf kinase inhibitors. J. Med. Chem. 2008, 51, 7049-7052. [CrossRef] [PubMed]

14. Ferreira, V.F.; Rocha, D.R.; Silva, F.C.; Ferreira, P.G.; Boechat, N.A.; Magalhães, J.L. Novel 1H-1,2,3-, 2H-1,2,3-, 1H-1,2,4- and 4H-1,2,4-triazole derivatives: A patent review (2008-2011). Expert Opin. Ther. Pat. 2013, 23, 319-331. [CrossRef] [PubMed]

15. Rostovtsev, V.V.; Green, L.G.; Fokin, V.V.; Sharpless, K.B. A stepwise Huisgen cycloaddition process: Copper(I)-catalyzed regioselective "ligation" of azides and terminal alkynes. Angew. Chem. 2002, 41, 2596-2598. [CrossRef]

16. Kolb, H.C.; Finn, M.G.; Sharpless, K.B. Click chemistry: Diverse chemical function from a few good reactions. Angew. Chem. 2001, 40, 2004-2021. [CrossRef]

17. Campbell-Verduyn, L.S.; Mirfeizi, L.; Dierckx, R.A.; Elsinga, P.H.; Feringa, B.L. ChemInform abstract: Phosphoramidite accelerated copper(I)-catalyzed [3 + 2] cycloadditions of azides and alkynes. Chem. Commun. 2009, 2139-2141. [CrossRef] [PubMed]

18. Donnelly, P.S.; Zanatta, S.D.; Zammit, S.C.; White, J.M.; Williams, S.J. 'Click' cycloaddition catalysts: Copper(I) and copper(II) tris(triazolylmethyl)amine complexes. Chem. Commun. 2008, 21, 2459-2461. [CrossRef] [PubMed]

19. Ozkal, E.; Llanes, P.; Bravo, F.; Ferrali, A.; Pericàs, M.A. Fine-tunable tris(triazolyl)methane ligands for copper(I)-catalyzed azide-alkyne cycloaddition reactions. Adv. Synth. Catal. 2014, 356, 857-869. [CrossRef]

20. Ye, W.J.; Xiao, X.; Wang, L.; Hou, S.C.; Hu, C. Synthesis of mono- and binuclear Cu(II) complexes bearing unsymmetrical bipyridine-pyrazole-amine ligand and their applications in azide-alkyne cycloaddition. Organometallics 2017, 36, 2116-2125. [CrossRef]

21. Han, B.F.; Xiao, X.; Wang, L.; Ye, W.J.; Liu, X.P. Highly active binuclear Cu(II) catalyst bearing an unsymmetrical bipyridine-pyrazole-amine ligand for the azide-alkyne cycloaddition reaction. Chin. J. Catal. 2016, 37, 1446-1450. [CrossRef]

22. Roth, G.J.; Liepold, B.; Müller, S.G.; Bestmann, H.J. Further improvements of the synthesis of alkynes from aldehydes. Synthesis 2004, 59-62. [CrossRef]

Sample Availability: Samples of the compounds $\mathbf{8 a}-\mathbf{8 y}$ are available from the authors.

(C) 2017 by the authors. Licensee MDPI, Basel, Switzerland. This article is an open access article distributed under the terms and conditions of the Creative Commons Attribution (CC BY) license (http:/ / creativecommons.org/licenses/by/4.0/). 